\title{
Estuaries and Shoreline Management Plans - lessons learned from Round 2.
}

\author{
Stephen Hunt, ABP Marine Environmental Research, shunt@abpmer.co.uk \\ Greg Guthrie, Royal Haskoning, g.guthrie@royalhaskoning.com \\ Nick Cooper, Royal Haskoning, n.cooper@royalhaskoning.com \\ Heidi Roberts, ABP Marine Environmental Research, hroberts@abpmer.co.uk
}

\begin{abstract}
As we now approach the completion of the 2nd round Shoreline Management Plans (SMPs) this paper provides a review of the implementation of the estuary guidance and lessons learned during its application. In particular, emphasis is placed on the need to retain flexibility within the estuary assessment process rather than applying a prescriptive approach with each estuary and corresponding assessment considered on a case by case basis. The review has drawn upon experience gained through the completion of a number of SMPs and estuaries around England and Wales. Although the points raised here apply directly to the UK they are also applicable to the management and understanding of estuaries throughout the world.
\end{abstract}

Keywords: Estuaries, Coastal Management, Coastal Processes, Coastal Dynamics

\section{Introduction}

Flood and coastal erosion management in England and Wales is led by the Environment Agency with support from coast protection authorities. The process for management is through the development of a hierarchy of plans, strategies and schemes to ensure a riskbased strategic approach is undertaken taking into account climate change to enable the effective direction of Government funds to the most vulnerable areas.

Shoreline management plans set the policy for stretches of coastline from which more detailed options and subsequent management actions (monitoring, realignment, maintaining or improving coastal defences) are investigated. A similar approach is undertaken for rivers with the policies being defined through the Catchment Flood management Plans (CFMP) and fluvial Flood Risk Management Strategies.

\section{Shoreline Management Plans}

Shoreline Management Plans (SMPs) are large scale plans which assess the risks and set long term policies for coastal flooding and erosion risk management in England and Wales. SMPs are the first stage in the delivery of sustainable shoreline management. Their policies are based on a detailed understanding of coastal processes and the developed, historic and natural environment of the coast and estuaries. They are the primary mechanism for directing flood and coastal erosion risk management activities and climate change adaptation is the cornerstone of this policy development.

Since the first SMPs were completed in the mid 1990s a number of additional data sources and management studies have been completed which contribute to SMP2 these include:

- UK Climate Projections 2009 (UKCP09) (Lowe et al, 2009) 
- Futurecoast (Defra, 2002)

- Catchment Flood Management Plans (carried out regionally by the Environment Agency)

- Flood and Coastal Erosion Strategies (carried out by both the EA and local authorities)

- Strategic Flood Risk Assessments (carried out by local authorities)

- Government and European research (Estuaries Research Programme)

- Various consultancy reports and peer reviewed journal articles

New legislation has also been introduced which needs to be taken into account such as the Water Framework Directive, PPS 20 and the Marine and Coastal Access Bill. To take account of this updated information and legislation a national programme for the review of the SMPs has just been completed (SMP2).

\section{Integration of Estuaries}

Estuaries are an important component of the coastal system and as the interface between the fluvial and marine environment present a number of issues for flood and erosion risk management. Furthermore estuaries around the UK exhibit a diverse range of morphologies and the interface of the estuaries and the open coast is often complex (Defra, 2002).

For effective and sustainable management of the coast an understanding of these interactions is essential. A review of the first round SMPs (MAFF, 2000) noted the varying degrees to which estuaries were considered within the management plans. To help address this issue procedural guidance for the second round of SMPs included specific assessment guidance (referred to as the "Appendix F assessment") for the integration of estuaries (Defra, 2006). The purpose of the Appendix $F$ assessment is to provide an initial analysis of how the estuary interacts with the coast in terms of physical processes and based on this suggest an appropriate landward extent of the SMP. The guidance aims to help an informed user follow a structured decision making process as opposed to recommending specific quantified threshold criteria (Pontee and Cooper, 2005).

The Appendix $\mathrm{F}$ assessment aims to address the following questions:

- Should the estuary be included in the SMP process?

- If so, how should the estuary be included?

- How far upstream should the estuary be included?

To consider these questions the following information is used to develop an understanding of physical processes within the estuary (Pontee and Cooper, 2005):

- The physical size of the estuary

- The physical process parameters of the estuary

- The degree of sediment supply from rivers and sediment exchange with the open coast

- The presence / absence of morphological features within the estuary and / or at the estuary mouth 
- The physical constraints within the estuary and / or along the adjacent coast (e.g. defences and / or geological controls)

- The potential for large-scale changes in alignment of defences within the estuary and / or along the open coast

\subsection{Should the estuary be included within the SMP?}

It has been found in practice that due to the large number watercourses that intersect with the coast around the UK (varying in size from small streams and springs through to large estuaries) and the varying degrees with which these influence physical processes on the open coast it is impractical and also unnecessary to subject all of these watercourses to the Appendix F procedure. This was encountered during the West Wales SMP where a total of 56 watercourses were identified as intersecting with the coast. To allow only the most significant watercourses to be considered within the full assessment a pre-appendix $F$ assessment scoping exercise was carried out whereby watercourses with limited interactions with the adjacent coast were not carried though to the more extensive assessment. This is generally based on a review of the watercourses using aerial photography, in doing this it is often possible to make an informed decision of the significance based on the size of the watercourse and any evidence of morphological interaction at the mouth (sand spits, interruption of drift patterns etc.). This allows the smaller watercourses to be scoped out of the assessment in a transparent manner with the larger watercourse being carried through to the full assessment.

The remaining watercourses that are not scoped out during this initial stage are then assessed using the following parameters:

- Significance of Water Exchange: To assess the significance of water exchange with the open coast a number of descriptive quantifiable parameters are assessed relative to other estuaries in the UK. These descriptive parameters are sourced from databases of estuarine parameters which have been compiled within the Estuary Database (ABPmer, 2009) from databases published by the Nature Conservancy Council (Davidson et al, 1991), EMPHASYS (2000), Dyer (2002) in Futurecoast and Townend (2005).

- Significance of sediment exchange: The assessment of the significance of sediment exchange takes into account factors such as tidal asymmetry, source / sink relationship between the estuary and the coast and any morphological features related to these processes (e.g. banks, spits or deltas).

- Significance of management issues: In addition to physical processes an understanding of management issues is also important, this can include historic reclamation, structures within the estuary that impact on interactions between the open coast and the estuary and consistency of approach with other management plans and the limits of these plans.

By evaluating the significance of each of the above three criteria using expert judgement a scoring is applied. Based on the total scores it can then be determined whether or not the estuary needs to be considered within the SMP. 
An example of typical features considered within an estuary assessment for the Dyfi Estuary in West Wales is shown in Figure 1. In this case the assessment procedure can be summarised as follows:

- Significance of water exchange: The estuary has a relatively large area of estuary and a macro tidal range. The mouth of the estuary has no geological hard points and therefore it is held in place dynamically.

- Significance of sediment exchange: Significant interactions with the coastal zone as shown by the presence of a delta and also a sand spit extending across the southern side of the estuary. The sediment exchanged with the estuary extends a large distance along the adjacent coast via littoral transport along the wide sandy foreshore.

- Significance of management issues: Termed as marginal as although large amounts of historical reclamation have occurred along the southern side of the estuary (railway line) the estuary has subsequently adjusted to this change in volume.

Therefore in this case the overall conclusion was to include this estuary within the open coast SMP.

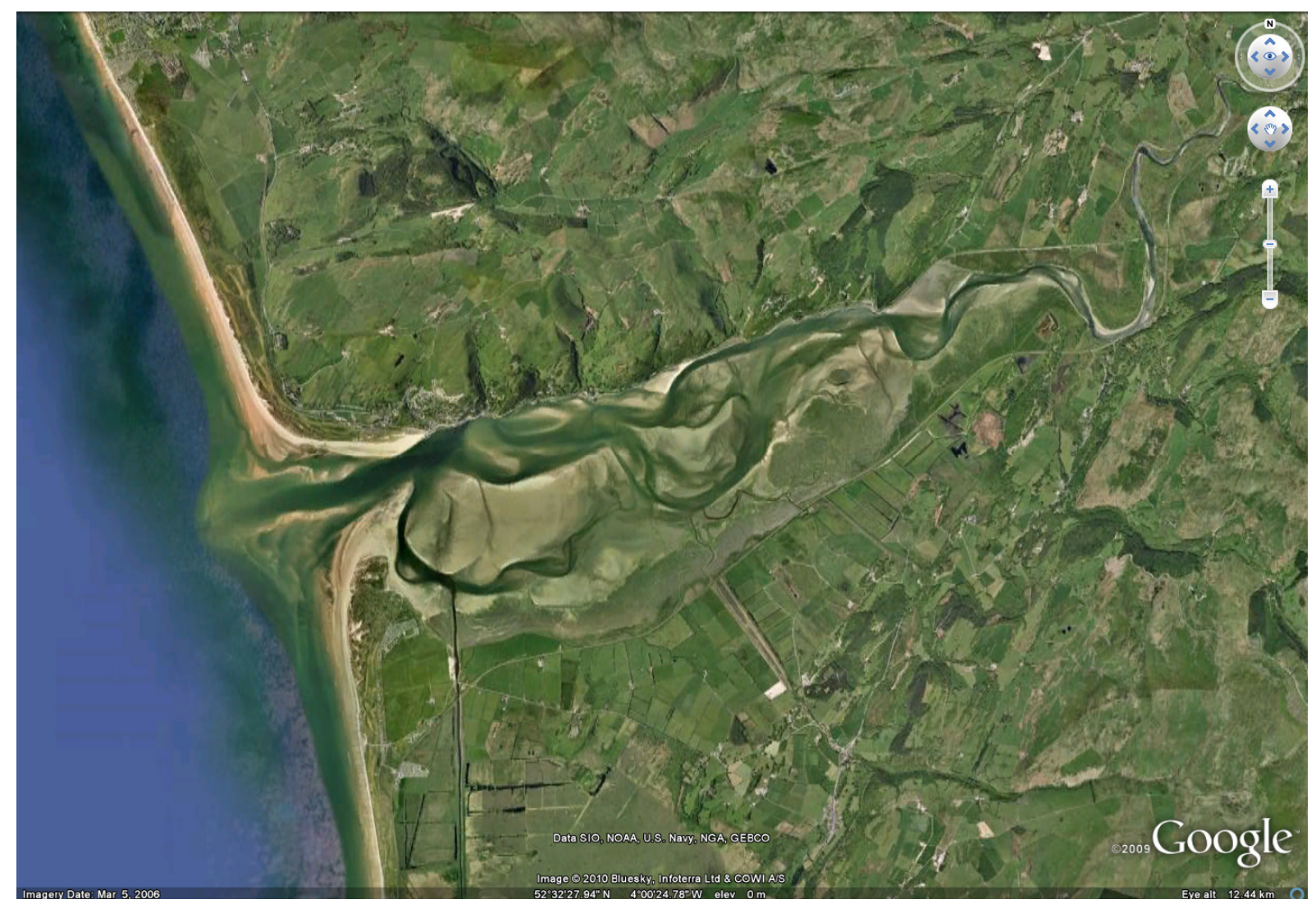

Figure1: Example estuary the Dyfi, West Wales (imagery from Google Earth)

Estuaries that are typically found to be insignificant in terms of physical process interactions were generally found to exhibit the following criteria:

- Insignificant water exchange due to small estuary area and / or small tidal range. 
- Insignificant sediment exchange small due to low suspended sediment loads within the water and/or a narrow rocky mouth with an adjacent open coast consisting of pocket bays or cliffs indicating limited littoral transport.

- Insignificant management issues due to undeveloped environment, low population, no historical reclamation.

In the case of these estuaries coastal management can be considered through a CFMP as opposed to the SMP.

\subsection{How should the estuary be included?}

Following the decision to include an estuary within the SMP a further decision is then made on how the estuary should be included within the SMP, this would typically be based on the following two options:

- Inclusion within the open coast SMP.

- Inclusion within a Estuary SMP (ESMP), this typically applies to large scale estuaries with complex management issues such as the Severn.

\subsection{How far upstream should the estuary be included?}

Determination of the landward extent to which an SMP should be considered is difficult to define in practice, along the open coast management boundaries are defined based on the extent of physical processes. Therefore based on this approach it seems intuitive that estuaries should be considered as far inland as their tidal limit as changes to the volume of the estuary can impact on tidal flows and therefore the lower estuary and the adjacent coast (Pontee and Cooper, 2005). However, in practice due to the large inland influence of tides it is often impractical and often unnecessary or inappropriate to assess estuaries as far upstream as the tidal limit. Other possible upstream boundaries include (Pontee and Cooper, 2005; Defra, 2006):

- Limit of wave influence.

- Limit of non-cohesive sediment exchange.

- Limit of continuity of habitats, development, risk zones, or flood reservoirs between the open coast and estuary.

- Limit of the CFMP.

- Limit as defined by the Schedule IV boundary.

In practice it has been found that often although the consideration of the physical interactions between the coast and the estuary are important for determining the extent of shoreline management it is not the only criteria that needs to be considered and management and political considerations also need to be included. For example in the case of the Fal Estuary in Cornwall the Appendix $F$ assessment scoped out the estuary based on physical processes. The hard geology of this Ria prevented significant sediment exchange with the coast and the relatively undeveloped nature of the estuary meant that there are no significant management issues for the SMPs to consider. However the estuary was not included in the adjacent CFMP and therefore needed to be included within the SMP to ensure flood risk management coverage. 


\section{$4 \quad$ Application of the guidance}

As the SMP2 process draws to a close it is appropriate to consider and reflect on the application of the Appendix $\mathrm{F}$ assessment guidance. Although these points reflect on the application of the Appendix $F$ assessment in the UK it is suggested that these points are also applicable in the context of estuary management elsewhere in the world.

\subsection{The importance of flexibility}

Although the Appendix $F$ assessment has provided a transparent repeatable methodology, it is important to remember the guidance was not intended to be prescriptive but instead provides a thought process within which expert judgement can be applied.

For example although the guidance was intended for use in estuaries there are a number of water bodies which also require assessment but do not fall cleanly into this category. Experience has shown that the guidance can be applied to other features such including straits (Menai Straits, North Wales), inlets and tidally influenced rivers.

\subsection{The importance of good scientific data}

The application of the Appendix $F$ assessment benefits from large baseline datasets collected as part of various estuary research programmes. Basic parameters available include:

- Size of estuary (intertidal / subtidal areas, areas of saltmarsh and other habitats).

- Tidal range and flows.

- Basic parameters of tidal asymmetry (source / sink relationship with the coast).

- Patterns of historical change.

- River flows.

The establishment of these datasets allow, in principle, all of the Appendix F assessments to be completed to a common level. Through the use of aerial photographs, bathymetric charts and basic tidal modelling software much of these basic parameters can be derived relatively easily and are considered a prerequisite for undertaking an analysis of estuaries. Experience of applying this guidance shows that aerial photos are particularly useful for estuaries where little study may have been undertaken and are useful for identifying as well as the overall size of the estuary morphological features and hence the potential interactions with the open coast.

\subsection{The value of expert local knowledge}

The Appendix $\mathrm{F}$ forms an important basis with which to consider the physical interactions between the open coast and the estuary in the absence of detailed site specific knowledge. However, if detailed expert knowledge exists this should be considered alongside the Appendix $\mathrm{F}$ assessment.

Overall an assessment process such as the Appendix $F$ procedure forms an excellent precautionary approach in the absence of detailed understanding but becomes less important on the context of a detailed understanding of local coastal dynamics. 


\subsection{The purpose of Appendix $F$}

It has been important throughout the estuary assessment process to always consider its primary purpose and to only apply it in the context for which it was intended. The assessment gives an initial analysis of the significance of an estuary in terms of coastal processes and provides a baseline description of data on which coastal management can be developed on within the SMP. This understanding of physical processes is a vital step within the SMP process but does not provide sufficient detail upon which to make flood and coastal erosion decisions.

Further to this, the extent of the shoreline management plan has to also be considered outside of context of coastal processes and in particular needs to consider the extent of other shoreline management plans. This is vital to ensure that gaps do not appear in management plans which in turn could lead to unsustainable and unsuitable coastal management decisions being made.

\section{The future}

SMP2 has built significantly on the first round of SMPs and the Appendix F assessment represents this ongoing process of improvement. Because of this process it is likely that the decisions on the inclusion and geographical limits of SMPs will be retained for future rounds of SMPs without any further work required on this aspect of the assessment process. SMP3 will probably primarily assess the appropriateness of the policies rather than reassess the boundaries of the management plan.

The reassessment of geographical boundaries is only likely to be required in situations where the coastal processes have radically altered. It is possible that a regime shift of this type could occur in the future as a result of climate change or possible large scale management practices such as realignment of flood defences and boundaries and would have to be revisited in these instances.

\section{Summary}

Overall the SMP estuaries guidance represents a transparent and consistent morphology for considering the inclusion of estuaries within SMPs. This process has been implemented across the UK and has proven to be a successful and effective way of considering the incorporation of estuaries into SMPs. This improves the SMP process when compared to the first round whereby the decision on which estuary inclusion was based was applied in an inconsistent way between the various segments of coast.

As the SMP2 process draws to an end it is appropriate to reflect on the following points for effective shoreline management:

- The existence of a clear set of guidelines so the decision-making process can be undertaken in a consistent way between different authors, scientists and managers.

- The need for a thorough understanding of coastal dynamics, oceanographic processes and coastal geomorphology so that the guidance can be applied in a meaningful and appropriate way.

- The flexibility to use the conclusions appropriately within the broader decision making process. 
It is concluded that practical application of the Appendix F procedure in the UK has provided a very effective way of determining the inclusion of estuaries within SMPs based on physical processes and represents a good template for similar management processes elsewhere in the world.

\section{References}

ABPmer. 2009. The Estuary Guide. Available online at: http://www.estuary-guide.net/

Davidson NC, Laffoley Dd, Doody JP, Way LS, Gordon J, Key R, Drake CM, Pienkowski MW, Mitchell R, Duff KL, 1991, Nature conservation and estuaries in Great Britain, Nature Conservancy Council, Peterborough, UK, 422 pages.

Defra, 2002, Futurecoast, Halcrow, Defra CD-Rom, 3 Vols.

Defra. 2006. Shoreline management plan guidance. Volume 1: Aims and requirements. Department for Environment Food and Rural Affairs, March 2006.

Dyer, K., 2002. FutureCoast Estuary Assessment. In: Halcrow, 2002, Futurecoast CD-ROM prepared for Defra.

EMPHASYS Consortium, 2000, Modelling Estuary Morphology and Process, produced by the EMPHASYS consortium for MAFF project FD1401, Estuaries Research Programme, Phase 1, December 2000. Report TR 111, HR Wallingford.

Lowe J. A., Howard T. P., Pardaens A., Tinker J., Holt J., Wakelin S., Milne G., Leake J., Wolf J., Horsburgh K., Reeder T., Jenkins G., Ridley J., Dye S., Bradley S. (2009), UK Climate Projections science report: Marine and coastal projections. Met Office Hadley Centre, Exeter, UK.

MAFF. 2000. A Review of Shoreline Management Plans 1996-1997. Ministry of Agriculture Fisheries and Food.

Pontee, N.I., Cooper, N.J. 2005. Including Estuaries in Shoreline Management Plans. Proceedings of the Institution of Civil Engineers. Maritime Engineering 158, March 2005, Issue MA1, Pages 33-40.

Townend IH, 2005, An examination of empirical stability relationships for UK estuaries, Journal of Coastal Research, 21(5), 1042-1053. 